\title{
Assessment of the Accuracy of Obturator Bulbs that are Produced by Using Cone Beam Computed Tomography and Stereolithography in Maxilloctemy Defects: An Ex Vivo Study
}

\author{
Sema Murat (D) \\ Department of Dentistry/Prosthetic Dentistry, Ankara University School of Dentistry, Ankara, Turkey
}

Cite this article as: Murat S. Assessment of the Accuracy of Obturator Bulbs that are Produced by Using Cone Beam Computed Tomography and Stereolithography in Maxilloctemy Defects: An Ex Vivo Study. JAREM 2018; 8(3): 186-90.

\begin{abstract}
Objective: We aimed to use cone-beam computed tomography (CBCT) as an alternative to conventional impression techniques in intraoral maxillectomy defects and to assess the volumetric accuracy of the obturator bulb sections placed in the defect area of obturator prosthesis fabricated using stereolithography.

Methods: The artificial defects created in human cadaver maxilla $(n=9)$ were scanned with CBCT. Total slices were captured and stored as digital imaging and communications in medicine (DICOM) images Thereafter, the images were imported and processed with Mimics Software (Mimics Innovation Suite, Materialize, Leuven, Belgium). From the DICOM images, 3D volumetric data of craniofacial hard and soft tissue were then segmented. Thereafter, the hard tissue and soft tissue data were imported into 3-MATIC software module where in virtual models were created and obturator bulb models were designed for maxillary defects considering defect surface borders. The production of obturator bulbs was conducted using a stereolithography device after $3 \mathrm{D}$ volumetric images were converted to stl. file format. A physical model of the defect was obtained using an A-type silicon impression material that represents the origins of the borders of the defects. The water displacement technique was used to measure silicon and resin bulb volumes. Data were sent to Minitab Release 15 statistical software program. One-way ANOVA was used to compare volumetric measurements obtained using the two techniques. Statistical significance was set at $p<0.05$.

Results: Although volumetric measurements obtained using СВCT images were lower than those obtained using silicon impression measurements, this difference was statistically insignificant $(p>0.05)$.

Conclusion: The production of obturator bulbs that fit into maxillary defects using 3D models created from CBCT images seems to be an achievable task.
\end{abstract}

Keywords: 3D printer, cone-beam computed tomography (CBCT), maxillectomy, obturator, stereolithography

\section{INTRODUCTION}

Treatment of paranasal tumors often requires palatal maxillectomy or radical maxillectomy. Surgical and prosthetic applications allow the treatment of post-maxillectomy patients as functional and aesthetic. Despite the advantages of surgical procedures, surgical reconstruction is not always possible due to the general condition of the patient and the size of the defect. Temporary and permanent obturators can be used in prosthetic reconstruction. The main purpose of prosthetic obstruction is to separate the oral cavity from the sinonasal cavity and to prevent hypernasal speech and fluid leakage to the nasal cavity. Obturators also restore chewing, swallowing, speech functions, and facial contour with the support they provide to the lips and cheeks and play a crucial role in helping patients overcome their social and psychological distress (1).

Rapid prototype production technology (rapid prototyping, $\mathrm{RP}$ ) or laser-layered manufacturing technique allows the production of computer-aided three-dimensional solid physical models layer-by-layer in a single step (2). This method, which has been rapidly advancing worldwide since 1995, is being used in product development, prototype, and mold manufacturing fields and has been used in the dentistry sector for only 3-5 years. The distinctive feature of rapid prototype techniques is the production of three-dimensional models by applying layers to layers with the help of technologies, such as laser and numerical control, not by removing and processing material 
from the main source as in computer-assisted design (CAD)computer-aided manufacturing (CAM) systems. The internal details of the complex structures and the undercut areas are created smoothly by the layering technique (2-4).

The use of different materials, production of layers by different methods, and bonding together revealed different rapid prototype techniques. Stereolithography (SLA), laminated object manufacturing, selective laser sintering, fused deposition modeling, three-dimensional modeling by spraying material (Inkjets, Photopolymer Phase Change Inkjets, and 3D Printing), and laser engineered net shaping are among the commercially important rapid prototype techniques available (2).

Rapid prototype production techniques are an alternative to conventional methods in the construction of facial prostheses. With the use of computer-aided imaging techniques, such as computed tomography (CT), magnetic resonance imaging (MRI), and laser surface scanners and optical systems, in creating anatomical details and profile, highly successful extraoral facial prostheses can be prepared using CAD-CAM and RP technologies with very good contours and tissue adaptation (5-8).

The prosthetic rehabilitation of intraoral deformities, such as maxillectomy defects, is generally provided with obturator prostheses prepared in conventional gypsum models without using 3D CAD and RP technologies.

The most important step in the process of making a functional and aesthetic prosthesis is to obtain the impression. Since the retention and stability will be formed with the support of the defective tissues in addition to the healthy tissues, obtaining the complete impression of the defect together with the tissues present in the mouth is important for prognosis of the prosthesis (9). The structural properties of the impression material used, the size of the defect, the undercuts present in the defect, the number and position of the remaining teeth, and the amount of mouth opening are factors that affect the accuracy and completeness of the measurement. In most cases, while removing the hardened material from the mouth, especially the irreversible hydrocolloid impression material, due to the vacuum effect, the patient feels great pain, and the impression material is exposed to tears and deformations. Bleeding of the tissues of the defect and adhesion of mucosal secretions to the surface of the impression also impair the clarity of the impression. Owing to restrictions in the opening of the mouth, insertion of the impression spoon and material into the mouth cannot be done as desired, and missing areas are formed in the impression (1).

$\mathrm{CT}$, based on the computer-based synthesis of images obtained from the body as thin radiographic sections, can be divided into two categories based on the $\mathrm{X}$-ray geometrical structure as follows: fan beam tomography (conventional or medical CT) and cone beam computed tomography (CBCT). Medical CT was used in implantology due to their three-dimensional image without superposition and distortion. However, medical tomography could not be used routinely because their effec- tive radiation doses are too high, expensive, difficult to apply, and cannot be found in any environment (10). In recent years, CBCT has emerged as an important diagnostic imaging technology, especially in the maxillofacial region as an alternative to conventional CTs. Dental volumetric tomography is more advantageous in clinical practice than in conventional CT with ease of application, acceptable radiation dose, rapid screening, being economical, high-quality images, and low artifacts (9-12).

Since 3D images of the anatomical structures are obtained by medical imaging techniques, such as $\mathrm{MRI}, \mathrm{CT}$, and $\mathrm{CBCT}$, there will be no problems, such as distortion, rupture, and gaps of the impression material, that can occur in the conventional method, much more compatible prostheses can be prepared, and thus the time spent in the clinic for adjustment of the prosthesis is shortened (13-17). In addition, medical imaging techniques do not use the impression material that stimulates the gag reflex in the patient. When conventional impressions are obtained and the models are casted, distortion due to contraction and expansion of materials is eliminated by the SLA technique. There are no negative factors, such as humidity control and air bubbles, in the final model as in conventional impression systems (15-17). In the context of the ex vivo study we planned, we aimed to overcome the problems and difficulties arising from conventional measurement systems by using $\mathrm{CBCT}$, to produce bulb sections that are located in the defect region of the obturator prostheses, and to evaluate their completeness by volume by using RP technology, such as SLA.

\section{METHODS}

Approval required for use of human cadaveric maxilla $(n=9)$ was obtained from the Department of Anatomy of Gülhane Military Medical Academy (1491-304-12/1539-604). Unilateral maxillectomies were performed to form localized defects of different dimensions extending to the middle line of the hard palate involving the crete region using surgical drills.

To prepare the models for obturator prostheses with SLA from the RP techniques, three-dimensional image data of the artificially created defects were obtained by CBCT device (3D Accuitomo 170; J. Morita Mfg. Corp., Kyoto, Japan) with 90 kVp and $5.0 \mathrm{~mA} 17.5$ irradiation time parameters wide area field of view (FOV; $80 \mathrm{~mm} \times 80 \mathrm{~mm}$ FOV, $0.160 \mathrm{~mm}^{3}$ (FOV80)).

The two-dimensional images of cadavers obtained using CBCT (DICOM file, Digital Imaging and Communications in Medicine format) were transferred to the commercial MIMICS (Mimics Innovation Suite; Materialise, Leuven, Belgium) software for realization of 3D reconstructions. In MIMICS software, hard tissue, soft tissue, and defect regions were modeled after certain segmentation procedures. Then, hard tissue and soft tissue data were transferred to the software's design module 3-MATIC (Mimics Innovation Suite), and virtual models were created. Obturator bulb models are designed for maxillary defects based on defect surface boundaries (Figures 1,2). Following the schematic design and process, the bulb models were transferred to MIMICS software, and border controls 
were done in radiological image sections. After converting the three-dimensional volumetric images to the Standard Tessellation Language (stl) file format, the stl files were transferred to the SLA device (Formlabs Form 2; Formlabs Inc., Somerville, MA, USA) to produce obturator bulbs in layers.

The physical model of the defect was obtained based on the defect starting limits with type A silicone impression material (Zhermack Elite HD; Badia Polesine RO, Italy). The volumes of silicone and resin bulbs were measured by water displacement technique. In this technique, by submerging the caliber removed from the obturator in the precision measurement, the cylinder was filled with water at room temperature, and the volume displaced was then calculated by subtracting the final volume of water from the first volume.

\section{Statistical Analysis}

Data were analyzed by Minitab Release 15 program (Minitab Ltd., PA, USA). The volumetric deviations between the two techniques were compared using one-way analysis of variance. A $p<0.05$ was accepted as statistically significant.

\section{RESULTS}

According to the results of one-way analysis of variance, there were differences between the volume of silicone measurement models of the defect and the volume of resin model produced by SLA, which was devised by 3D virtual model of the defects that were segmented from CBCT images $(p>0.05)$. Volume values obtained by CBCT images were found to be lower than silicone values ( $p>0.05)$ (Figure 1).

\section{DISCUSSION}

In recent years, in obtaining impression, which is the most critical stage in the prosthetic rehabilitation of maxillary defects, the use of imaging systems, such as CBCT, which is a revolutionary tool for dentistry, emerged as an alternative to conventional methods (13-17).

There are a limited number of studies on the production of obturators using digital technologies and imaging systems, such as CBCT, CT, and MRI (13-20). In their in vivo study, Jiao et al. (18) designed the defect section of the obturator prostheses on the 3D models of the $\mathrm{CT}$ images of patients with maxillary defect and then realized the production of the obturator bulb as in our study with SLA technology. The impression of the remaining soft tissues and teeth was obtained by conventional method, and the obturators were completed on the prepared gypsum models. According to the results of a limited number of studies conducted for use of CBCT images in the production of dental models, CBCT has been reported to provide a more complete model production than conventional scale models, but it shows higher deviations than oral scanners when the model is produced with 3D printers from CBCT data (21). Further studies are needed to defend the use of CBCT data as a reliable method to obtain models of maxillary defects with $3 \mathrm{D}$ printers.

Elbashti et al. (22) obtained the conventional and digital measurements of polyurethane toothless maxillary defects in the in
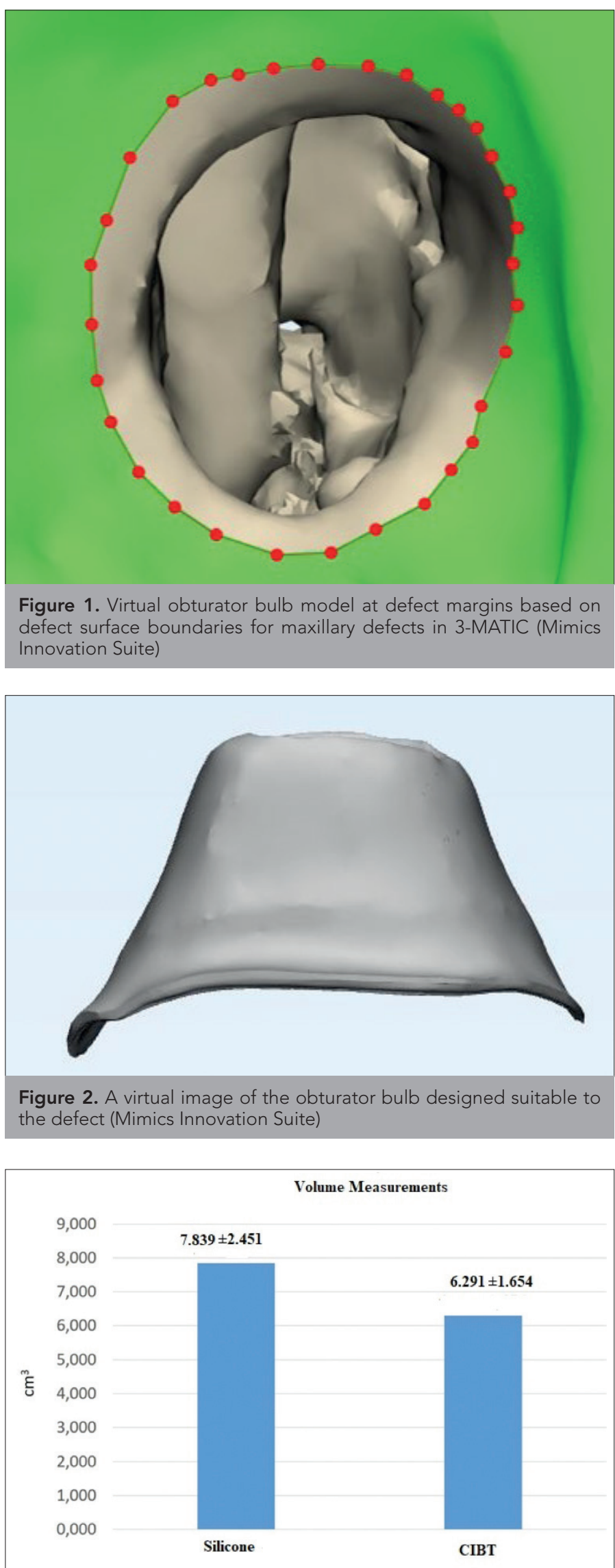

Figure 3. Volume showing average and standard deviation values $\left(\mathrm{cm}^{3}\right)$ 
vitro study using silicone impression material and surface scanner and intraocular scanner and compared the completeness of the 3D models with CBCT data as reference. As a result of their study, there are more deviations reported in the conventional impressions due to the dimensional changes caused by the expansion of dental gypsum material.

According to the results of their study using the water displacement technique, similar to our study, with 3D scanner and CBCT to determine the volume of the maxillary defects in cadavers, Kamburoğlu et al. (23) found that the results obtained from the $3 \mathrm{D}$ scanner provide values closer to the silicone impression of the defect that is used as the gold standard compared with CBCT.

Kamburoğlu et al. (24) reported that when the volumes calculated by CBCT using artificial defects prepared in the buccal margin of the implants placed on the cadaveric jaws are compared with the volumes of the measurements obtained with the silicone impression material, the volumes calculated by CBCT are lower than the physical volume values, similar to the findings of our study. Similar results were reported by Agbaje et al. (25) who reported that there are difficulties in volume calculation, especially due to the difficulty in the segmentation of small-size defects with CBCT. In addition, changes in voxel dimensions and cross-sectional thicknesses have been reported with significant changes in the measurements performed with CBCT data. In the context of our ex vivo research, the evaluation of obturator bulbs prepared from single brand CBCT devices and using image sections without using different parameters is one of the limitations of our study.

\section{CONCLUSION}

Considering data obtained within the scope of the limitations of our research, we concluded that in addition to the advantages of the use of CBCT in the creation of 3D anatomy of the maxillary defects, with the use of digital technologies, the preparation of obturator bulbs compatible with the defect was possible.

Ethics Committee Approval: Ethics committee approval was received for this study from the Ethics Committee of Gülhane Military Medical Academy, Department of Anatomy (Local Ethics Committee Review Number 1491-304-12/1539-604).

\section{Informed Consent: N/A}

Peer-review: Externally peer-reviewed.

Acknowledgements: The author is grateful to Tümer Arıtürk of SPAC Consulting, Ankara, Turkey, for statistical analysis.

Conflict of Interest: The author has no conflict of interest to declare.

Financial Disclosure: This study was supported by 2214- The Scientific and Technological Research Council of Turkey.

\section{REFERENCES}

1. Beumer J, Curtis TA. Restoration of acquired hard palate defects. In Beumer J, Curtis TA, Marunick M, editors. Maxillofacial rehabilita- tion: prosthodontic and surgical considerations. 1 st ed. St Louis: Ishiyaku EuroAmerica; 1996.p.226-329.

2. Alharbi N, Wismeijer D, Osman RB. Additive Manufacturing Techniques in Prosthodontics: Where Do We Currently Stand? A Critical Review. Int J Prosthodont 2017; 30: 474-84. [CrossRef]

3. Sun J, Zhang FQ. The application of rapid prototyping in prosthodontics. J Prosthodont 2012; 21: 641-4. [CrossRef]

4. Peng Q, Tang Z, Liu O, Peng Z. Rapid prototyping-assisted maxillofacial reconstruction. Ann Med 2015; 47: 186-208. [CrossRef]

5. Ciocca L, Scotti R. CAD-CAM generated ear cast by means of a laser scanner and rapid prototyping machine. J Prosthed Dent 2004; 92: 591-5. [CrossRef]

6. Karayazgan-Saracoglu B, Gunay Y, Atay A. Fabrication of an auricular prosthesis using computed tomography and rapid prototyping technique. J Craniofac Surg 2009; 20: 1169-72. [CrossRef]

7. Liacouras P, Garnes J, Roman N, Petrich A, Grant GT. Designing and manufacturing an auricular prosthesis using computed tomography, 3-dimensional photographic imaging, and additive manufacturing: a clinical report. J Prosthet Dent 2011; 105: 78-82. [CrossRef]

8. Nuseir A, Hatamleh M, Watson J, Al-Wahadni AM, Alzoubi F, Murad M. Improved Construction of Auricular Prosthesis by Digital Technologies. J Craniofac Surg 2015; 26: 502-5. [CrossRef]

9. Dos Santos DM, de Caxias FP, Bitencourt SB, Turcio KH, Pesqueira AA, Goiato MC. Oral rehabilitation of patients after maxillectomy. A systematic review. Br J Oral Maxillofac Surg 2018; 56: 256-66. [CrossRef]

10. Scarfe WC, Farman AG, Sukoviç P: Clinical app $\neg$ lications of ConeBeam Computed Tomography in dental practice. J Can Dent Assoc 2006; 72: 75-80.

11. Kamburoğlu K. Use of dentomaxillofacial cone beam computed tomography in dentistry. World J Radiol 2015; 7: 128-30. [CrossRef]

12. Fourie Z, Damstra J, Gerrits PO, Ren Y. Accuracy and repeatability of anthropometric facial measurements using cone beam computed tomography. Cleft Palate Craniofac J 2011; 48: 623 30. [CrossRef]

13. Michelinakis $\mathrm{G}$. The use of cone beam computed tomography and three dimensional printing technology in the restoration of a maxillectomy patient using a dental implant retained obturator. J Indian Prosthodont Soc 2017;17: 406-11. [CrossRef]

14. Tasopoulos T, Kouveliotis G, Polyzois G, Karathanasi V. Fabrication of a 3D Printing Definitive Obturatör Prosthesis: a Clinical Report. Acta Stomatol Croat 2017; 51: 53-8. [CrossRef]

15. Park JH, Lee KS, Lee JY, Shin SW. Fabricating a Maxillary Obturatör Using an Intraoral Digital Impression: A Case History Report. Int J Prosthodont 2017; 30: 266-8. [CrossRef]

16. Rodney J, Chicchon I. Digital Design and Fabrication of Surgical Obturatörs Based Only on Preoperative Computed Tomography Data. Int J Prosthodont 2017; 30: 111-2. [CrossRef]

17. Londono J, Abreu A, Baker PS, Furness AR. Fabrication of a definitive obturatör from a 3D cast with a chairside digital scanner for a patient with severe gag reflex: a clinical report. J Prosthet Dent 2015; 114: 735-8. [CrossRef]

18. 1. Jiao T, Zhu C, Dong X, Gu X. Rehabilitation of maxillectomy defects with obturatör prostheses fabricated using computer-aided design and rapid prototyping: a pilot study. Int J Prosthodont 2014; 27: 480-6. [CrossRef]

19. Kim MS, Lee JY, Shin SW. Fabricating an obturatör using rapid prototyping to design the framework: a case report. Int J Prosthodont 2014; 27: 439-41. [CrossRef]

20. Huang Z, Wang XZ, Hou YZ. Novel method of fabricating individual trays for maxillectomy patients by computer-aided design and rapid prototyping. J Prosthodont 2015; 24: 115-20. [CrossRef]

21. Wesemann C, Muallah J, Mah J, Bumann A. Accuracy and efficiency of full arch digitalization and 3D printing: A comparison between 
desktop model scanners, an intraoral scanner, a CBCT model scan, and stereolithographic 3D printing. Quintessence Int 2017; 48: 4150.

22. Elbashti M, Hattori M, Sumita Y, Aswehlee A, Yoshi S, Taniguchi H, et al. Creating a digitized database of maxillofacial prostheses (obturators): A pilot study. J Adv Prosthodont 2016; 8: 219 23. [CrossRef]

23. Kamburoğlu K, Kurşun Ş, Kılıç C, Özen T. Accuracy of virtual models in the assessment of maxillary defects. Imaging Sci Dent 2015; 45: 23-9. [CrossRef]
24. Kamburoğlu K, Murat S, Kılıç C, Yüksel S, Avsever H, Farman A, et al. Accuracy of CBCT images in the assessment of buccal marginal alveolar peri-implant defects: effect of field of view. Dentomaxillofac Radiol 2014; 43: 20130332. [CrossRef]

25. Agbaje JO, Jacobs R, Michiels K, Abu-Ta'a M, van Steenberghe D. Bone healing after dental extractions in irradiated patients: a pilot study on a novel technique for volume assessment of healing tooth sockets. Clin Oral Investig 2009; 13: 257-61. [CrossRef] 